\title{
Los préstamos del BID a las instituciones de control presupuestario
}

\author{
Carlos Santiso
}

I

organismos financieros internacionales están mostrando un renovado interés por lograr que las economías emergentes mejoren la gestión del presupuesto nacional y fortalezcan la integridad de las finanzas públicas. Asimismo, están redescubriendo el papel de los parlamentos nacionales y las entidades fiscalizadoras superiores en la supervisión de los procesos presupuestarios y la rendición de cuentas en las finanzas públicas. El Banco Interamericano de Desarrollo (BID) otorga a tales instituciones, para consolidar su contribución al proceso presupuestario, préstamos multilaterales con potencialidades aún inexploradas y cuya eficacia podría acrecentarse. La segunda generación de reformas de las instituciones presupuestarias mejorará su capacidad técnica y eficiencia operacional y supone tanto el fortalecimiento de la gobernabilidad de las finanzas públicas, en particular la promoción de vínculos más eficaces entre las entidades fiscalizadoras superiores y las comisiones parlamentarias de presupuesto y cuentas públicas, como la autonomía financiera e independencia política de las entidades fiscalizadoras superiores.

\section{Economista político}

School of Advanced International Studies, Johns Hopkins University,

Washington, D.C.

• csantiso@jhu.edu 


\section{Explorando nuevos horizontes}

La calidad del proceso presupuestario es considerada cada vez más un factor esencial para el buen gobierno. La transparencia y la supervisión de ese proceso son indispensables para mejorar la gestión de las finanzas públicas, asegurar la debida rendición de cuentas por parte del gobierno y reducir la corrupción. En consecuencia, tanto el proceso presupuestario como la responsabilidad e integridad en la gestión de las finanzas públicas son hoy objeto de renovado escrutinio.

En el decenio de 1990 surgieron reformas de segunda generación para mejorar la elaboración del presupuesto público y la gestión de las finanzas públicas en las economías emergentes. Los enfoques tradicionales se concentraban principalmente en mejorar el desempeño y la eficacia dentro del poder ejecutivo, sobre todo en los ministerios de finanzas, los organismos de ejecución, la autoridad tributaria y los bancos centrales. Sin embargo, en los últimos años se ha prestado mayor atención al fortalecimiento de las instituciones de gestión económica más allá del poder ejecutivo, y al mejoramiento de los mecanismos de supervisión y rendición de cuentas. Esta segunda generación de reformas se ha debido en parte a nuevos descubrimientos sobre los factores que determinan la calidad de la política económica, y a la necesidad de equilibrar las facultades presupuestarias discrecionales del ejecutivo con mecanismos que aseguren la rendición de cuentas por parte del gobierno. Esto se ha traducido en un renovado interés en la credibilidad e integridad de las finanzas públicas y en el aporte de los parlamentos nacionales y las entidades fiscalizadoras

\footnotetext{
$\square$ El autor se especializa en la economía política de la reforma de la gobernabilidad y la rendición de cuentas de las finanzas públicas en los mercados emergentes, particularmente en lo que se refiere a la elaboración del presupuesto público y la auditoría externa. Escribió parte de este ensayo mientras era investigador invitado en la Oficina Anticorrupción del Ministerio de Justicia, Seguridad y Derechos Humanos de Argentina, en julio-agosto de 2003. Las opiniones expresadas en el presente artículo son las del autor y no reflejan necesariamente las de las instituciones mencionadas. El autor agradece a Linn Hammergren, Javier Santiso, Lynette Asselin, María Isabel dos Santos, Joachim Wehner, Warren Krafchik, John Williamson, Enrique Paixão, Alfredo Fólica, Arturo Aylwin, Julio Rodolfo Comadira, Miriam Ivanega, Delia Ferreira Rubio, Néstor Baragli, Manuel Garrido, Patricia Llanos, Hernán Llanos, Simon Gill, Yasuhiko Matsuda y a un crítico anónimo por su estímulo, comentarios y sugerencias.
}

superiores ${ }^{1}$ a la rendición de cuentas del gobierno en materia presupuestaria. ${ }^{2}$

La inclusión de consideraciones de gobernabilidad en la agenda de desarrollo ha llevado a los organismos financieros internacionales a ampliar el alcance de sus acciones para promover la reforma económica y mejorar la gestión financiera gubernamental. Estos organismos apoyan de manera significativa el refuerzo de los órganos de gestión de las finanzas públicas en las economías emergentes, en el contexto más amplio de las reformas institucionales de segunda generación (Santiso, 2004c y 2003a; Burki, Perry y otros, 1998). La reducción de la brecha entre los aspectos económicos y políticos de la gobernabilidad es una marcada característica de las nuevas teorías de reforma del sector público, tendencia que se hace evidente en el enfoque del BID.

En noviembre de 2000, el Banco Mundial adoptó una estrategia destinada a orientar su participación en asuntos de gobernabilidad (Banco Mundial, 1997 y 2000), mientras que en julio del 2003 el BID actualizó su programa para la modernización del Estado (BID, 2003). Estas acciones ponen de relieve la importancia asignada a la contribución de los parlamentos y las entidades fiscalizadoras superiores para hacer efectivas las responsabilidades gubernamentales en la gestión de las finanzas públicas.

El interés de los organismos financieros internacionales en mejorar la rendición de cuentas en ese sector obedece a consideraciones fiduciarias y de desarrollo. Para reducir el riesgo fiduciario en créditos vinculados a políticas y de apoyo directo al presupuesto público es indispensable contar con sistemas de administración presupuestaria vigorosos y confiables en los países receptores (Santiso, s/f). Además, impulsados por comprobaciones recientes de la poca eficacia de la

\footnotetext{
${ }^{1}$ Las entidades fiscalizadoras superiores (supreme audit institutions) se conocen por diversos nombres en los distintos países (oficinas generales de contabilidad, de contraloría, de auditoría o tribunales de cuentas, etc.). En este artículo la expresión "entidades fiscalizadoras superiores" hace referencia a las instituciones encargadas de la auditoría externa de los programas y cuentas públicas del gobierno.

${ }^{2}$ Véase Santiso (s/f, 2004a y 2004b), Haggard y McCubbins (2001), Schedler, Diamond y Plattner (1999), y Mainwaring y Welna (2003).
} 
asistencia prestada y de la existencia de cooptación y corrupción estatales, los organismos financieros internacionales han mejorado sus instrumentos de diagnóstico para evaluar la calidad del proceso presupuestario público y la eficacia de los mecanismos de rendición de cuentas en las finanzas gubernamentales. ${ }^{3}$ El Programa de gasto público y rendición de cuentas financieras (PEFA), por ejemplo, es una iniciativa de varios donantes iniciada en diciembre de 2001, que tiene como objetivo armonizar los estándares internacionales de contabilidad, auditoría y control interno del sector público en los países en desarrollo y en transición. ${ }^{4}$ Las agencias bilaterales de cooperación establecidas en el Grupo Utstein (Alemania, Noruega, Países Bajos y Reino Unido) también han respaldado activamente las instituciones de rendición de cuentas en los países en desarrollo. ${ }^{5}$

En forma análoga, en el contexto de la ampliación de la Unión Europea, el Tribunal de Cuentas Europeo trabaja desde 1993 para aumentar la capacidad institucional de las entidades fiscalizadoras superiores en los países candidatos de Europa central y oriental, como parte del proceso de convergencia hacia los estándares aplicados por la Unión Europea a la gestión y auditoría de las finanzas públicas. ${ }^{6}$ El programa SIGMA, ${ }^{7}$ creado en 1992 por la Comunidad Europea y la Organización de Cooperación y Desarrollo Económicos (OCDE), ha contribuido a la modernización de dichas entidades y al reforzamiento de los mecanismos de control externos para el sector público de los países candidatos. La posibilidad de acceder a la Unión Europea constituyó un incentivo muy especial para afianzar los sistemas de rendición de cuentas de las finanzas públicas en los países que ingresarían a ella. El proceso establecido para observar la aplicación de los criterios acordados en Copenhague en 1997 permitió que las reformas se ampliaran y consolidaran gradualmente, lo que llevó a la incorporación de un primer grupo de 10 países en mayo de 2004.

\footnotetext{
3 Véase DFID (2001 y 2002), Brobäck y Sjölander (2002) y PEFA (2003).

${ }^{4}$ Véase www.pefa.org.

${ }^{5}$ Véase, en particular, Centro Anticorrupción Utstein, www.u4.no. Para más información sobre proyectos financiados por donantes véase también www.respondanet.com.

${ }^{6}$ Cabe señalar que, paradójicamente, el Tribunal de Cuentas Europeo no ha podido certificar las cuentas de la Unión Europea en los últimos ocho años. Esto refleja la dificultad para remediar las disfunciones estructurales de los sistemas de administración financiera.

7 Support for Improvement in Governance and Management in Central and Eastern European Countries.
}

En el caso de América Latina y el Caribe, las iniciativas para el fortalecimiento institucional de los ministerios de finanzas y los organismos tributarios cuentan con el respaldo de los bancos multilaterales de desarrollo y del Gobierno de los Estados Unidos, por medio de la Oficina General de Contabilidad estadounidense y de la Agencia de los Estados Unidos para el Desarrollo Internacional (USAID). Ya en las décadas de 1920 y 1930, Estados Unidos prestó asistencia técnica a países latinoamericanos para que instituyeran bancos centrales y modernizaran sus sistemas financieros gubernamentales (Drake, 1989). Las misiones Kemmerer a los países andinos ayudaron a crear oficinas de contraloría y auditoría sólidas, responsables de la contabilidad y auditoría central de las finanzas del gobierno. Del mismo modo, desde comienzos de la década de 1990 el Banco Mundial, el BID y la USAID han ayudado a los países latinoamericanos a modernizar su administración financiera mediante el establecimiento de sistemas de gestión integrados (Dorotinsky y Matsuda, 2002). A lo largo de esa década, Argentina, Bolivia, El Salvador, Guatemala, Honduras, Nicaragua y Venezuela recibieron préstamos y donaciones para asistencia técnica destinados a mejorar sus sistemas de gestión financiera gubernamental.

En este ensayo se analizan los préstamos del BID a las instituciones de control presupuestario y de rendición de cuentas de las finanzas públicas en América Latina y el Caribe, principalmente los otorgados a entidades fiscalizadoras superiores y a parlamentos nacionales. El respaldo del BID a la consolidación de los organismos de auditoría externa y de las comisiones de presupuesto parlamentarias forma parte de acciones más amplias destinadas a mejorar la administración financiera del sector público en los países prestatarios. No obstante, en este trabajo se argumenta que la segunda fase de reformas económicas obliga a trazar nuevos planes para fortalecer las instituciones vinculadas a la gobernabilidad de las finanzas públicas (Krueger 2000), lo que implica considerar los factores de economía política que determinan la reforma de la gobernabilidad y el desarrollo institucional. En concreto, para asegurar una mayor supervisión y más integridad en la gestión de las finanzas públicas es preciso acrecentar los vínculos funcionales entre las instituciones que participan en el proceso presupuestario y el sistema de control nacional.

El presente trabajo consta de cuatro secciones. A continuación, en la sección II se examina brevemente el nuevo enfoque de los organismos financieros internacionales frente a la gestión de las finanzas públicas, que hace hincapié en la transparencia y la rendición de 
cuentas. En la sección III se analiza el otorgamiento de préstamos en condiciones favorables a las entidades fiscalizadoras superiores y a los parlamentos de América Latina y el Caribe por parte del BID. Se argumenta que existen posibilidades aún inexploradas de aumentar la eficacia de las entidades fiscalizadoras superiores y los parlamentos nacionales en la elaboración del presupuesto público, lo cual supone considerar la economía política de la reforma institucional.
Además de mayores recursos técnicos y eficiencia operativa, la segunda generación de reformas requiere el fortalecimiento de la independencia política y la autonomía financiera de las entidades fiscalizadoras superiores, así como la promoción de vínculos más eficaces entre éstas y las comisiones parlamentarias de cuentas públicas. La sección IV, por último, ofrece algunas observaciones sobre los aspectos políticos de la rendición de cuentas en las finanzas públicas.

\section{II}

\section{Repensar la rendición de cuentas en} las finanzas públicas

Los organismos de rendición de cuentas del sistema financiero público son un elemento esencial del nuevo paradigma de la economía del desarrollo y determinan los recursos necesarios para llevar a cabo reformas económicas de segunda generación más allá del Consenso de Washington (Krueger, 2000; Kuczynski y Williamson, 2003; Santiso, 2004c y 2003a). En la primera fase de la reforma, las prescripciones normativas del Consenso de Washington impulsaron el predominio del poder ejecutivo en la elaboración del presupuesto público y la formulación aislada de políticas económicas. Sin embargo, el abuso del gobierno por decreto efectuado por presidentes fuertes, así como la delegación de la autoridad legislativa, con frecuencia llevaron a neutralizar los mecanismos de rendición de cuentas, a cooptar a las entidades fiscalizadoras superiores y a restringir el papel de los parlamentos en el proceso presupuestario (Santiso, 2001a y 2001b). En consecuencia, las reformas de segunda generación que se promueven en la actualidad suponen restablecer los mecanismos que aseguran transparencia, supervisión y rendición de cuentas en la elaboración y gestión del presupuesto.

\section{Gobernabilidad y finanzas públicas}

El buen gobierno es un factor clave para que un país logre un desarrollo económico y social sostenible. El interés de los organismos financieros internacionales por enfrentar los dilemas de gobernabilidad en los países en desarrollo obedece en gran medida a la necesidad urgente de abordar las causas estructurales de la corrupción. Este flagelo se convirtió en una preocupación fundamental para el Banco Mundial en 1996, cuando James Wolfensohn, entonces su nuevo presidente, comprometió a la organización a combatir el "cáncer de la corrupción", cuyos efectos corrosivos en la gestión económica y en la eficacia de la asistencia son hoy bien conocidos. El Banco Mundial, por lo tanto, comenzó a respaldar programas para fortalecer el Estado de derecho, los sistemas judiciales, los sistemas de administración de las finanzas públicas y los mecanismos parlamentarios de supervisión de las cuentas públicas (Banco Mundial, 2000). Asimismo, en 1997 adoptó la estrategia de incorporar medidas anticorrupción en todas sus políticas y prácticas crediticias.

Según la definición estándar del Banco Mundial, el concepto de gobernabilidad expresa 'la manera en que se ejerce el poder en la administración de los recursos económicos y sociales de un país para alcanzar el desarrollo' (Banco Mundial, 1992, p. 1). ${ }^{8}$ Abarca la forma de régimen político, el proceso mediante el cual se ejerce la autoridad en la administración de los recursos económicos y sociales para el desarrollo, y la capacidad de los gobiernos para idear, formular y aplicar políticas y desempeñar funciones. Sin embargo, "la importancia de la credibilidad y el compromiso del gobierno en materia de reformas de política se ha dejado de lado como condición fundamental para la eficacia de las reformas económicas' (Ahrens, 2001,

\footnotetext{
${ }^{8}$ En este artículo, las citas entre comillas simples han sido traducidas del inglés.
} 
p. 75). La credibilidad de la política económica depende en gran medida de la eficacia de los mecanismos de rendición de cuentas (Haggard y McCubbins, 2001; Santiso, 2004a).

\section{Aproximaciones a la reforma de la goberna- bilidad}

El concepto de gobernabilidad plantea dificultades a los bancos multilaterales de desarrollo, que no quieren ser considerados políticos y por eso adoptan la doctrina de la neutralidad (Santiso, 2001c y 2004d). Uno de los temas más conflictivos es la distinción entre los aspectos económicos y políticos de la gobernabilidad. Aunque el Banco Mundial reconoce que el concepto es intrínsecamente político, hace hincapié en que su propia participación mediante préstamos, asistencia técnica y asesoramiento en materia de políticas se encuadra solamente en dimensiones económicas. No obstante, señala que la naturaleza del sistema político está fuera del alcance del mandato establecido en el Convenio Constitutivo de la institución. En forma análoga, el Banco Asiático de Desarrollo (BAsD), que fue el primer banco regional en adoptar una política de gobernabilidad en 1995, define la "buena gobernabilidad" como "una acertada gestión para el desarrollo" basada en cuatro "pilares" interrelacionados: rendición de cuentas, transparencia, predictibilidad y participación. Para el BAsD, "buena gobernabilidad es buen gobierno" (BAsD, 1995 y 1999). El Banco Africano de Desarrollo (BAfD) tiene una concepción parecida (BAfD, 2000).

El enfoque del BID con respecto a la reforma estatal y la modernización del sector público tiene varios rasgos en común con el del Banco Mundial, en particular su sesgo técnico (Santiso, 2000). En teoría, y del mismo modo que el Banco Europeo de Reconstrucción y Desarrollo (BERD, 1992), el BID adopta un punto de vista político más explícito frente a la reforma de la gobernabilidad y, en general, es menos reacio a involucrarse en áreas políticamente sensibles y hacer frente a la economía política del desarrollo institucional. La expansión de su mandato en 1994 amplió sus objetivos políticos, que ahora incluyen la consolidación de la democracia. La política del BID sobre la modernización del Estado se articuló por primera vez en 1996 y se actualizó en 2003 para incorporar aspectos relacionados con la economía política de la reforma, en particular los sistemas de partidos, las normas electorales y las relaciones entre los poderes ejecutivo y legislativo (BID, 2003). Las autoridades del banco reconocen que la política influye en el desarrollo y que, en consecuencia, sus préstamos y su asistencia técnica deberían abordar más activamente consideraciones de economía política (Payne, Zovatto y otros, 2002).

Es innegable que la introducción de la agenda de gobernabilidad llevó a las instituciones financieras internacionales a ampliar el alcance de sus intervenciones y adentrarse en territorios inexplorados, entre ellos la reforma judicial, el fortalecimiento parlamentario y la lucha contra la corrupción. Entre 1996 y 2000, el Banco Mundial inició más de 600 programas e iniciativas relacionados con la gobernabilidad en 95 países, y de 1997 a 1998 llevó a cabo 169 programas de reforma de la administración civil del Estado en 80 países. Según estimaciones recientes, también emprendió 126 proyectos de reforma del sector público en América Latina entre 1982 y 2002, por un total de 12.000 millones de dólares (Fuhr y Krause, 2003). La mayoría de estos proyectos, generalmente vinculados a políticas que hacen hincapié en la reforma fiscal, se concentran en la elaboración del presupuesto público y la gestión financiera del gobierno. En forma análoga, la reforma legal y judicial se ha convertido en un componente medular de la cartera de proyectos del Banco Mundial vinculados a la gobernabilidad (Santiso, 2004d). A partir de 1991, el Banco Mundial ha financiado 480 proyectos en 84 países que se relacionan con elementos de reforma legal y judicial, o los incluyen, por un valor de 380 millones de dólares. Y entre 1991 y 2001 aprobó 35 proyectos dedicados exclusivamente a la reforma judicial. ${ }^{9}$ También ha establecido instrumentos de crédito con fines específicos y ha actualizado su propia capacidad para evaluar el desempeño judicial y promover la reforma judicial, para lo cual ha realizado evaluaciones del sector judicial desde 1994 y estudios institucionales y de gobernabilidad más exhaustivos desde 1999.

Del mismo modo, entre 1993 y 2001 el BID aprobó 18 préstamos y 65 operaciones de cooperación técnica para reformar los sistemas judiciales y modernizar la administración de justicia en 21 de sus 26 países miembros. Dichas operaciones representaron una inversión de 461 millones de dólares (Biebesheimer y Payne, 2001; Santiso, 2003b).

\footnotetext{
${ }^{9}$ La Vicepresidencia Legal del Banco ha brindado asesoría legal a más de 87 países en más de 45 áreas especializadas desde 1986. La capacitación en materia de reforma legal y judicial también se ha convertido en una actividad principal del World Bank Institute (WBI).
} 
En 1996, la Junta de Gobernadores del Fondo Monetario Internacional (FMI) también exhortó a la institución a promover la 'gobernabilidad en todos sus aspectos, lo que implica velar por el imperio de la ley, mejorar la eficiencia y la rendición de cuentas en el sector público y combatir la corrupción, como elementos indispensables de un marco en el cual las economías puedan prosperar'. Desde entonces, el papel del FMI en materia de gobernabilidad se ha ampliado considerablemente, para incluir factores de transparencia, rendición de cuentas y predictibilidad de las finanzas públicas (FMI, 1997 y 2001). El Fondo ha expresado su estrategia de reforma de la gobernabilidad bajo el manto neutral de su pericia técnica, concentrándose en aquellos aspectos económicos de la gobernabilidad que podrían tener consecuencias macroeconómicas importantes y que afectan la aplicación de las reformas económicas. En 1997, la institución adoptó normas que especificaban que sólo se involucraría "en los aspectos económicos de la gobernabilidad" (FMI, 1997, p. 3), a saber, la transparencia de las cuentas del gobierno, la eficacia de la administración de los recursos públicos y la estabilidad del marco regulatorio para la actividad del sector privado. No obstante, la posición del FMI con respecto al contexto político de los países prestatarios continúa siendo ambigua, como lo demuestra su actuación respecto de Indonesia o Argentina.

Que el FMI se involucre en la reforma de la gobernabilidad interna de un país se debe en parte al nuevo papel que el Fondo desempeña en la administración de la cuenta de capital y a su promoción del ajuste estructural desde la década de 1980. Estas nuevas funciones implican necesariamente una participación más constante en la reforma de las políticas de los países prestatarios, más allá del manejo de crisis pasajeras. La supervisión, los créditos y la asistencia técnica son las principales vías por las que el FMI fomenta la buena gobernabilidad. En cuanto a la supervisión, el Fondo ha promovido enérgicamente estándares y códigos de buenas prácticas por medio de consultas conforme al Artículo IV de su Convenio Constitutivo, sobre todo respecto de asuntos fiscales.

Desde fines de la década de 1990, el FMI ha reconocido la importancia de la transparencia en la administración de la política monetaria y financiera; en 2001 adoptó un Código de buenas prácticas de transparencia fiscal. ${ }^{10} \mathrm{El}$ cumplimiento de estos estándares por los

${ }^{10}$ El FMI ha definido doce áreas clave, entre ellas contabilidad, fiscalización, anticorrupción, supervisión bancaria, gobernabilidad, países se evalúa en los Informes sobre observancia de códigos y normas (IOCN). Hasta fines de junio de 2002 se habían elaborado 264 informes referentes a 80 países, de los cuales se han publicado 193. Estos instrumentos de diagnóstico complementan a los del Banco Mundial que evalúan la calidad de los procesos de las finanzas públicas, entre ellos los exámenes del gasto público (PER) y las evaluaciones de la capacidad financiera de los países (CFAA). Aunque tienen diferentes mandatos y desempeñan distintas funciones, las instituciones financieras internacionales están procurando coordinar y armonizar mejor sus instrumentos de evaluación a lo largo del ciclo de las finanzas públicas, desde la recaudación de los ingresos hasta la administración de los gastos (PEFA, 2003).

\section{Control presupuestario}

Los parlamentos y las entidades fiscalizadoras externas cumplen un papel destacado en la elaboración del presupuesto nacional, la rendición de cuentas en las finanzas públicas y el control de la corrupción en la nueva estrategia de modernización del Estado adoptada por el BID en julio de 2003. ${ }^{11}$ Después de una primera ola de reformas que se concentraban en la eficiencia y efectividad de los sistemas de gestión financiera gubernamentales dentro del ejecutivo, la nueva estrategia reconoce la importancia fundamental de los mecanismos de transparencia y supervisión externa en el proceso presupuestario. El papel de los parlamentos nacionales en esta materia está siendo redescubierto en la región.

En su esfuerzo por consolidar la gobernabilidad democrática, el BID (2003) hace hincapié en la necesidad de "reforzar la capacidad institucional del poder legislativo", especialmente mediante el respaldo a programas concebidos para "el fortalecimiento de sistemas de asesoría técnica que mejoren la calidad de las leyes y ayuden a que la función presupuestaria, de fiscalización y control se ejerza sobre bases técnicas y objetivas" (p. 12). Además, la estrategia permite al BID brindar asistencia para "el incremento de la capacidad técnica e independencia funcional de las instituciones

transparencia fiscal y transparencia de las políticas monetaria y financiera.

${ }^{11}$ La estrategia se concentra en cuatro áreas de intervención prioritaria: el sistema democrático; el imperio de la ley y la reforma de la justicia; el Estado, los mercados y la sociedad, y la gestión pública. 
de control del desempeño de los poderes públicos, como Contralorías, Tribunales de cuentas, Auditorías, Defensorías, Fiscalías y Procuradorías" (p. 13).

Los parlamentos y las entidades fiscalizadoras superiores, en su calidad de tales, deben considerarse como elementos clave de los sistemas de control nacionales. El BID reconoce que "los órganos de fiscalización, supervisión y control no siempre tienen la independencia, objetividad y capacidad técnica que les permitan velar por la observancia de la ley..." (BID,
2003, p. 5). "Los problemas de corrupción son de alguna forma expresión de la debilidad del Estado de derecho en su conjunto, pero llaman la atención también sobre la debilidad de la administración financiera del Estado" (p. 5). El enfoque del BID subraya la necesidad de "fortalecer la capacidad fiscal del Estado y mejorar la eficiencia y la transparencia de la gestión del gasto" y de implantar "sistemas integrales de gestión financiera y contable y el fomento de la transparencia al público de la información fiscal" (p. 18).

\section{III}

\section{Otorgamiento de préstamos a instituciones de control presupuestario}

En los últimos años, las instituciones financieras internacionales han "redescubierto" la importancia del tema del presupuesto público y, en especial, del papel de los parlamentos y las entidades fiscalizadoras externas en la gestión presupuestaria. En consecuencia, se está reevaluando el aporte de las instituciones legislativas a la formulación y supervisión de políticas presupuestarias, y se reconoce cada vez más que ellas son esenciales para asegurar la rendición de cuentas por parte del gobierno y la integridad de la gestión de las finanzas públicas. Se ha recalcado especialmente la importancia de las comisiones parlamentarias de presupuesto y cuentas públicas, sobre todo en los sistemas presidenciales. Las mejores prácticas para la transparencia presupuestaria establecidas por la Organización de Cooperación y Desarrollo Económicos (OCDE, 2001a) incluyen consideraciones sobre el papel de los parlamentos en el proceso presupuestario, con lo cual llevan la delantera al Código de buenas prácticas de transparencia fiscal del FMI, que tiende a limitarse a la gestión presupuestaria dentro del poder ejecutivo. Esta limitación también es evidente en el respaldo que brindan los organismos financieros internacionales a los países en transición para reformar sus procedimientos presupuestarios. En efecto, la asistencia técnica ha tendido a concentrarse ya sea en el lado del gasto, al prestar apoyo a las oficinas de los primeros ministros y los ministerios de finanzas, o bien en el lado de la recaudación, al brindar asesoramiento sobre reformas tributarias y reforzar la capacidad de la autoridad tributaria.
No obstante, los bancos multilaterales de desarrollo comenzaron recientemente a aumentar su respaldo a las instituciones que formulan y supervisan las políticas presupuestarias, para lo cual han colaborado con las entidades fiscalizadoras superiores y los parlamentos nacionales. Aunque los programas de esos bancos continúan estando limitados por cierto sesgo técnico que les impide abordar temas de gobernabilidad delicados, como los vínculos insatisfactorios entre los tribunales de cuentas y las comisiones parlamentarias de cuentas públicas, la situación está empezando a cambiar. En efecto, las relaciones disfuncionales entre los componentes individuales de los sistemas de control e integridad en las finanzas públicas merman la eficacia de los mecanismos de control externos y los de supervisión parlamentaria del presupuesto en América Latina; en general, dichos componentes tienden a actuar de manera aislada. Esto permitió que la corrupción floreciera casi sin limitaciones en países como Argentina durante la presidencia de Carlos Menem (19891999), o Perú durante el gobierno de Alberto Fujimori (1990-2000), debido a que las instituciones encargadas de asegurar la integridad y la adecuada rendición de cuentas fueron particularmente vulnerables a la cooptación.

En última instancia, como se argumenta en este ensayo, la eficacia de los sistemas nacionales que velan por la integridad y probidad en las finanzas públicas depende en gran medida de la sinergia entre sus diversos componentes, a saber: los sistemas contables gubernamentales, los mecanismos de auditoría interna, 
las entidades de control externas, los tribunales administrativos y penales y las comisiones parlamentarias de supervisión (Diamond, 2002). A continuación se examina brevemente el respaldo brindado por el BID tanto a los parlamentos nacionales como a las entidades fiscalizadoras superiores.

\section{Préstamos a parlamentos nacionales}

El fortalecimiento de la función parlamentaria es un campo relativamente nuevo para los bancos multilaterales de desarrollo. En la actualidad se tiene más conciencia del papel de los parlamentos en el proceso presupuestario y de su responsabilidad en el proceso de rendición de cuentas por parte del gobierno. ${ }^{12} \mathrm{Su}$ rol en la elaboración del presupuesto es fundamental, pues contribuyen a hacer efectivas las responsabilidades democráticas y a proporcionar los frenos y contrapesos necesarios para compensar la discrecionalidad del ejecutivo en los sistemas presidenciales. La tendencia general es a que el cuerpo legislativo participe más en el proceso presupuestario, pero debe demostrar que puede hacerlo de manera responsable y garantizar la disciplina fiscal. Las parlamentos latinoamericanos deben fortalecer los mecanismos institucionales que promueven intervenciones responsables desde el punto de vista fiscal.

Como muestra el cuadro 1, el BID aprobó siete operaciones de crédito en América Latina y el Caribe entre 1994 y 2003, por un total de 45 millones de dólares. Este monto es parte de programas de reforma parlamentaria que suman más de 60 millones de dólares. El objetivo declarado de la financiación del BID es afianzar las funciones representativas, legislativas y fiscalizadoras de los parlamentos. La mayor parte de los fondos señalados está destinada a inversiones en áreas como la creación de infraestructura física, mejora de la tecnología de la información y gestión de recursos humanos.

Una característica destacada de los préstamos del BID a este sector es su interés especial en aumentar la participación del parlamento en el proceso presupuestario, ante todo mejorando el trabajo de las comisiones, su planificación estratégica y su capacidad de investigación. Las asambleas legislativas son instituciones fundamentales en la formulación de la política presupuestaria (por medio de las comisiones que aprue-

12 Véase Krafchik y Wehner (1998), OCDE (2001b), Manning y Stepenhurst (2002) y Wehner (2003). ban el presupuesto estatal) y en el control de la ejecución del presupuesto (por medio de la comisión de cuentas públicas). Un primer conjunto de iniciativas respaldadas por el BID tiene como objetivo reforzar las estructuras internas y procedimientos de esas asambleas que dan forma al proceso legislativo. Hace hincapié en las comisiones parlamentarias involucradas en el proceso presupuestario, en la etapa de aprobación o de supervisión (es decir, las comisiones de presupuesto y de cuentas públicas). Las comisiones de cuentas públicas, consideradas ahora una importante institución presupuestaria, son un vínculo esencial entre la responsabilidad del parlamento de asegurar la rendición de cuentas del gobierno en materia de finanzas públicas y la función de contraloría externa realizada por las entidades fiscalizadoras superiores (Wehner, 2002). Un segundo conjunto de iniciativas del BID apunta a acrecentar la capacidad de los parlamentos para efectuar un análisis presupuestario independiente, para lo cual ayuda a establecer o reforzar centros de investigación parlamentarios y oficinas presupuestarias que asesoran a las comisiones de cuentas públicas. Las operaciones de crédito del BID han sido relativamente exitosas en ayudar a los parlamentos a mejorar sus servicios de investigación y asesoramiento. En el caso de Venezuela, han contribuido a la creación de oficinas de presupuesto parlamentarias, aunque éste es un ejemplo aislado.

El fortalecimiento de las potestades presupuestarias de los parlamentos también refleja un desplazamiento gradual de poder entre la rama ejecutiva y la legislativa en los sistemas de gobierno presidenciales latinoamericanos. Las asambleas legislativas se están volviendo más fuertes, a medida que ganan terreno los partidos de oposición. Aunque históricamente estuvieron dominadas por mayorías pertenecientes al partido gobernante o relacionadas con él, esto ha comenzado a cambiar y muchos presidentes ya no controlan las mayorías legislativas. Esta nueva dinámica de las relaciones entre el ejecutivo y el legislativo tiene un efecto considerable en la formulación de políticas económicas y la elaboración del presupuesto público. Las asambleas legislativas están reafirmando gradualmente sus facultades de control del presupuesto, en parte como resultado de la asertividad adquirida recientemente por la oposición parlamentaria. La situación de gobierno dividido, en la que el presidente ya no controla a la asamblea legislativa, se está generalizando cada vez más en la región, y crea nuevas restricciones a las facultades discrecionales del poder ejecutivo en la elaboración del presupuesto público. La ola de 
CUADRO 1

América Latina: Préstamos del Banco Interamericano de Desarrollo a parlamentos nacionales

\begin{tabular}{|c|c|c|c|c|c|c|}
\hline \multirow[t]{2}{*}{ Año } & \multirow[t]{2}{*}{ País } & \multirow[t]{2}{*}{ Título } & \multicolumn{3}{|c|}{ Cantidad (millones de dólares) } & \multirow{2}{*}{$\begin{array}{c}\text { Años } \\
\text { Período de } \\
\text { desembolso }\end{array}$} \\
\hline & & & Total & $\begin{array}{l}\text { Préstamo } \\
\text { del BID }\end{array}$ & $\begin{array}{l}\text { Financiación de } \\
\text { contrapartida }\end{array}$ & \\
\hline 2003 & Perú & $\begin{array}{l}\text { Programa de fortalecimiento institucional } \\
\text { del Congreso peruano }\end{array}$ & 10 & 7 & 3 & 4,5 \\
\hline 2000 & Honduras & Modernización del Congreso hondureño & 3,25 & 2,60 & 0,65 & 4 \\
\hline 2000 & $\begin{array}{l}\text { República } \\
\text { Dominicana }\end{array}$ & $\begin{array}{l}\text { Programa para modernizar el Congreso Nacional y la } \\
\text { Contraloría General }\end{array}$ & $\begin{array}{c}28 \\
(25,55)^{\mathrm{a}}\end{array}$ & 22,30 & 5,70 & 3 \\
\hline 1999 & Colombia & Modernización del Congreso de la República & 10 & 6 & 4 & $\ldots$ \\
\hline 1999 & El Salvador & Modernización y fortalecimiento de la asamblea legislativa & 4,40 & 3,50 & 0,90 & 4 \\
\hline 1996 & Panamá & Proyecto para modernizar la asamblea legislativa & 4,10 & 2,80 & 1,30 & 4 \\
\hline 1994 & Perú & Desarrollo institucional del poder legislativo & 3,74 & 2,70 & 1,04 & $\cdots$ \\
\hline Total & & & 61,04 & & & \\
\hline
\end{tabular}

Fuente: Sobre la base de proyectos aprobados hasta octubre de 2003, www.iadb.org.

a Cantidad asignada al parlamento.

activismo legislativo en el proceso presupuestario en México se debe en parte al surgimiento de una oposición asertiva después que el Partido Revolucionario Institucional, que había detentado el poder por muchos años, perdiera en 1977 la mayoría en el parlamento (Carbonell, 2002; Weldon, 2002). En Brasil, el parlamento ha sido tradicionalmente el escenario privilegiado para introducir asignaciones y modificaciones presupuestarias con fines electorales (Samuels, 2002). Incluso en Argentina, país con partidos relativamente disciplinados, la elaboración del presupuesto público ha sido en los últimos tiempos objeto de más conflictos y regateos que en el pasado (Eaton, 2002; Jones, 2001).

El caso de México es ilustrativo. Desde 1997, este país ha llevado a cabo una serie de reformas institucionales orientadas a fortalecer el papel del parlamento en la formulación y supervisión de las políticas presupuestarias. En 1998 se elevó la capacidad técnica para el examen independiente del presupuesto con el establecimiento en la cámara baja del Centro de Estudios en Finanzas Públicas (CEFP), bien dotado de recursos humanos y financieros. La capacidad de investigación del parlamento mexicano ya era relativamente importante en esa época, porque existían el Servicio de Investigación y Análisis (SIA) de la biblioteca parlamentaria y el Instituto de Investigaciones Legislativas del Senado de la República (IILSEN), creado en 1985 para brindar asesoramiento técnico general al Senado. En consecuencia, el parlamento está ahora mejor equipado que antes para cumplir con sus responsabilidades presupuestarias. Cabe señalar que uno de los principales obstáculos para la participación legislativa en el proceso presupuestario suele residir en su incapacidad para involucrarse en él, más que en restricciones a las facultades presupuestarias del parlamento. Vemos así que al evaluar el papel real de las asambleas legislativas en la el control presupuestario es preciso tener en cuenta las capacidades técnicas con que cuentan. En 1999, después de cuatro años de negociaciones, se estableció una oficina de contraloría externa para asistir al parlamento en la supervisión de las finanzas públicas federales y la certificación de las cuentas públicas. La Auditoría Superior de la Federación (ASF) fue creada como organismo asesor de la cámara baja del parlamento, para ayudar en el examen de la instrumentación del presupuesto y la certificación de las cuentas públicas del gobierno federal. En 2000, el parlamento también aprobó la Ley Superior de Fiscalización de la Federación. Como se dijo más atrás, el surgimiento de una oposición parlamentaria efectiva como resultado de las elecciones de 1997 - oposición que a la larga derrotó en las elecciones de 2000 al que fuera durante mucho tiempo el partido gobernante- aumentó considerablemente los incentivos y las capacidades para que el poder legislativo efectuara una fiscalización presupuestaria eficaz.

El reconocimiento cada vez mayor de la importancia de los parlamentos en el control eficaz del 
presupuesto, permite a éstos acceder a fuentes de análisis independientes, en lugar de depender de los datos proporcionados por el gobierno. El acceso a la información presupuestaria es estratégico, dado que es la oposición la que tiene mayores alicientes para aumentar los recursos con que cuenta el parlamento para analizar el presupuesto y fiscalizar eficazmente el desempeño gubernamental (Messick, 2002; Rubio Llorente, 1993). Contar con personal profesional capaz y con conocimiento experto dentro del poder legislativo es condición necesaria para que las asambleas legislativas puedan ejercer sus funciones de fiscalización de manera adecuada y responsable. La falta de funcionarios profesionales y la ausencia o debilidad de los servicios de asesoramiento a las comisiones parlamentarias son graves obstáculos para llevar a cabo con eficacia las funciones presupuestarias de las asambleas legislativas. Los parlamentarios, incluidos los que pertenecen a las comisiones de presupuesto y cuentas públicas, tienen sus propios asesores políticos. Sin embargo, las comisiones parlamentarias permanentes carecen de los servicios de asesoría e investigación necesarios y de asesores permanentes técnicamente calificados y con memoria institucional. Esto también está comenzando a cambiar. Aunque menos poderosas que la Oficina Congresional del Presupuesto (Estados Unidos), hoy tienden a aparecer poco a poco incipientes oficinas de presupuesto en los parlamentos de toda América Latina. Esto se debe al reconocimiento cada vez mayor tanto de las deficiencias actuales en este campo como del aporte que pueden hacer los parlamentos a la fiscalización presupuestaria. Chile, México y Venezuela ya tienen incipientes oficinas parlamentarias de presupuesto, mientras que Argentina y Colombia consideran su establecimiento.

El BID, en una actitud comprensible, se muestra renuente a involucrarse en la reforma de la estructura de incentivos que configuran el papel de los parlamentos en el proceso presupuestario, sobre todo en lo que se refiere a la calidad del proceso legislativo, el papel de los partidos políticos y grupos parlamentarios, las relaciones entre el ejecutivo y el legislativo y las normas electorales. En efecto, se trata de áreas muy complejas y delicadas, que no se prestan a soluciones de parche ni a la trasposición de respuestas institucionales. Lo que se requiere frente a ellas es una cabal comprensión de los intereses e incentivos que moldean el comportamiento de los individuos en contextos institucionales. El BID, que pertenece a los gobiernos prestatarios y emplea a prestigiados forjadores de políticas originarios de la región, está en inmejorables condicio- nes de comprender esta dinámica. Sin embargo, sus operaciones crediticias tienden a apuntar al funcionamiento interno de los parlamentos, y no miran la elaboración y fiscalización del presupuesto público como un proceso integral. De esto resulta que con frecuencia esas operaciones no logran generar el efecto sistémico que podrían tener sobre la calidad del proceso presupuestario y el papel del parlamento en la fiscalización del presupuesto público.

La naturaleza del régimen político y la calidad del sistema político partidario, según se reconoce de manera creciente, son variables clave. En particular, 'los partidos opositores son los que tienen el mayor incentivo para controlar al gobierno' (Messick, 2002, p. 2) y garantizar la fiscalización efectiva de la administración financiera gubernamental. En muchos sistemas parlamentarios, como el del Reino Unido, el presidente de la comisión de cuentas públicas es un representante del principal partido opositor. En última instancia, el grado de cohesión y disciplina de los partidos políticos determina en gran medida la eficacia de las instituciones de rendición de cuentas y la calidad de las relaciones entre el ejecutivo y el legislativo. Es comprensible entonces que estos sean temas extremadamente difíciles y áreas de participación altamente conflictivas para las instituciones financieras internacionales.

Un obstáculo fundamental para reforzar la fiscalización parlamentaria del presupuesto es que en el parlamento sólo la oposición, de haberla, tiene interés en hacer más eficaz esa fiscalización y, por lo tanto, incentivos para crear o fortalecer la capacidad de la asamblea legislativa para realizar una evaluación independiente. El fortalecimiento de las instituciones parlamentarias de presupuesto debe abordarse necesariamente en el marco más amplio de las relaciones entre los poderes ejecutivo y legislativo en los sistemas de gobierno presidenciales.

En Venezuela, por ejemplo, con el apoyo del BID se creó en 1997 la Oficina de Asesoría Económica y Financiera de la Asamblea Nacional (OAEF). Su objetivo era mejorar los servicios de asesoramiento técnico del parlamento en materia de política fiscal. Esta nueva estructura pudo aprovechar fuentes de investigación y análisis legislativo ya existentes, como el Servicio Autónomo de Información Legislativa (sAIL) creado en 1994. No obstante, las tensiones entre el poder ejecutivo y la asamblea legislativa desde que el presidente Hugo Chávez asumió el gobierno socavaron el funcionamiento de la OAEF: esta se cerró en febrero de 2000, se reabrió en junio de ese mismo año al reactivarse el préstamo del BID que había sido suspendido, y en 2002- 
2003 estuvo nuevamente bajo presión (Rojas y Zavarce, 2004). El caso de Venezuela es de particular interés, porque allí el BID se convirtió, quisiéralo o no, en un actor en la pugna entre el poder ejecutivo y el legislativo por las potestades presupuestarias.

\section{Préstamos a entidades fiscalizadoras superio- res}

Prestar a las entidades fiscalizadoras superiores es también algo relativamente nuevo para los bancos multilaterales de desarrollo (Llanos, 2002). En teoría, estas entidades actúan como un mecanismo de control fundamental para garantizar que el gobierno responda por la manera en que administra las finanzas públicas. Son instituciones estatales independientes, responsables de fiscalizar el desempeño del gobierno y las cuentas públicas y, en algunos casos, de supervisar el sistema de auditoría interna. ${ }^{13}$ Aunque se ha avanzado mucho en los últimos años para mejorar el cumplimiento de las disposiciones legales y financieras en el gasto gubernamental, todavía queda mucho por hacer para asegurar la evaluación adecuada del desempeño del gobierno y el efectivo control externo de la ejecución del presupuesto. En muchos países latinoamericanos estas tareas continúan siendo deficientes y los informes de auditoría externa no logran mejorar el proceso de elaboración del presupuesto.

Hace relativamente poco que los bancos multilaterales de desarrollo comenzaron, aunque modestamente, a prestar ayuda a las auditorías generales y a reforzar las entidades fiscalizadoras superiores. El respaldo del BID a estas instituciones ha creado expectativas en muchos países, porque tiene lugar en una etapa fundamental del proceso de reforma y modernización del Estado. A medida que los países entienden que la existencia de instituciones sólidas de rendición de cuentas es fundamental para asegurar una gestión acertada de las finanzas públicas y la eficacia de los mecanismos anticorrupción, sobre todo en los sistemas de gobierno presidenciales de América Latina, el apoyo del BID a las entidades fiscalizadoras superiores se inserta en el contexto más amplio del fortalecimiento de la administración financiera gubernamental. En tal

${ }^{13}$ En algunos países, las entidades fiscalizadoras superiores también actúan como organismo supervisor de la auditoría interna del gobierno. Aunque este ensayo se concentra en la auditoría externa, cabe señalar que los vínculos (o ausencia de ellos) entre las funciones de auditoría internas y externas son fundamentales (Diamond, 2002). calidad los préstamos del BID constituyen un poderoso mecanismo para afianzar la mano de los reformadores. El caso de Chile es particularmente ilustrativo, porque el plan de financiación de 25 millones de dólares acordado con el BID en 2001 ha permitido a la entidad fiscalizadora superior chilena desarrollar su programa de consolidación institucional, lo que habría sido imposible sin ese respaldo. Desde 1993, el BID ha aprobado nueve operaciones crediticias para el fortalecimiento institucional de las entidades fiscalizadoras superiores latinoamericanas, por más de 50 millones de dólares en el contexto de proyectos con este propósito por más de 90 millones de dólares, mientras se tramitan dos nuevas operaciones por más de 12 millones de dólares. Al aprobarse estas últimas, la cartera de préstamos alcanzaría a unos 65 millones de dólares (cuadro 2). Estos créditos, si bien siguen siendo considerados "innovadores" - y por lo tanto, "pilotos"por el BID, se han ido intensificando desde el año 2000.

No obstante, la dimensión financiera de estas operaciones varía de un país a otro, tanto en términos absolutos como relativos. En consecuencia, las expectativas acerca de sus resultados deben ser realistas. El cuadro 3 muestra la contribución de los préstamos del BID al presupuesto de las entidades fiscalizadoras superiores en Brasil, Chile, Colombia y Nicaragua.

Hay varios aspectos que merecen destacarse. En primer lugar, los préstamos bilaterales representan sólo una parte del presupuesto de las instituciones beneficiarias, pero aun así esa parte puede ser considerable en algunos casos. Mientras que en Nicaragua el BID contribuye con casi el 30\% del presupuesto anual de las entidades fiscalizadoras superiores, en Brasil la cifra apenas llega al 1\%. En Chile y Colombia los préstamos del BID representan alrededor del $18 \%$ y el $11 \%$, respectivamente, del presupuesto anual de esas entidades. Como era de esperarse, la cifra tiende a ser más alta en países más pequeños, pues el BID considera estos proyectos como "préstamos innovadores". En segundo lugar, las asignaciones presupuestarias a las entidades fiscalizadoras superiores han tendido a aumentar en los últimos años, aunque su porción del presupuesto nacional continúa siendo pequeña: en Brasil, el presupuesto del Tribunal de Cuentas de la Unión representa sólo el $0,08 \%$ del presupuesto federal (TCU, 2002, p. 38). En tercer lugar, la financiación de contrapartida suele ser considerable, como lo es en Brasil (50\%), Chile (40\%) o Colombia (45\%). Estos últimos dos aspectos reflejan la importancia cada vez mayor que los gobiernos nacionales adjudican al fortalecimiento de las funciones de auditoría externa. Por tanto, al evaluar los resultados de 
CUADRO 2

\section{América Latina: Préstamos del Banco Interamericano de Desarrollo} a entidades fiscalizadoras superiores nacionales

\begin{tabular}{|c|c|c|c|c|c|c|}
\hline \multirow[t]{2}{*}{ Año } & \multirow[t]{2}{*}{ País } & \multirow[t]{2}{*}{ Título } & \multicolumn{3}{|c|}{ Cantidad (millones de dólares) } & \multirow[b]{2}{*}{$\begin{array}{c}\text { Período de } \\
\text { ejecución } \\
\text { (años) }\end{array}$} \\
\hline & & & Total & $\begin{array}{l}\text { Préstamo } \\
\text { del BID }\end{array}$ & $\begin{array}{l}\text { Financiación de } \\
\text { contrapartida }\end{array}$ & \\
\hline 2004 & Perúa $^{\mathrm{a}}$ & $\begin{array}{l}\text { Modernización de la Contraloría General y } \\
\text { desconcentración del sistema nacional de control }\end{array}$ & 14,50 & 10,15 & 4,3 & 4 \\
\hline 2002 & Brasil & Modernización del Tribunal de Cuentas de la Unión & 10 & 5 & 5 & 3 \\
\hline 2002 & Chile & Modernización de la Contraloría General de la República & 25 & 15 & 10 & 4,5 \\
\hline 2002 & Nicaragua & $\begin{array}{l}\text { Programa de Modernización de la Contraloría General } \\
\text { de la República }\end{array}$ & 6 & 5,40 & 0,60 & 4 \\
\hline 2000 & Colombia & $\begin{array}{l}\text { Fortalecimiento de la Contraloría General de la República } \\
\text { (CGR) y la Auditoría General de la República }\end{array}$ & 42 & 23 & 19 & 4 \\
\hline 2000 & Honduras $^{\mathrm{d}}$ & $\begin{array}{l}\text { Fortalecimiento y modernización de la Dirección de } \\
\text { Probidad Administrativa }\end{array}$ & 3 & 2,5 & 0,50 & $\ldots$ \\
\hline 2000 & $\begin{array}{l}\text { República } \\
\text { Dominicana }\end{array}$ & $\begin{array}{l}\text { Programa para modernizar el Congreso Nacional y la } \\
\text { Contraloría General }\end{array}$ & $\begin{array}{c}2,45 \\
(28) \\
\mathrm{b}\end{array}$ & $\underset{c}{2,45}$ & $\ldots$ & 3 \\
\hline 1999 & El Salvador & Modernización y fortalecimiento del Tribunal de Cuentas & 4 & $\cdots$ & $\cdots$ & $\ldots$ \\
\hline 1994 & Uruguay & Modernización del Tribunal de Cuentas & 1,50 & 1,41 & 0,09 & $\ldots$ \\
\hline 1993 & Caribe & Entidades fiscalizadoras de los países del Caribe & 0,81 & 0,60 & 0,21 & $\cdots$ \\
\hline Total & & & 109,26 & 64,91 & & \\
\hline
\end{tabular}

Fuente: Proyectos aprobados o en preparación hasta mayo de 2004, www.iadb.org.

a Operación de crédito en fase de aprobación.

b Monto global del proyecto para modernizar el parlamento y la entidad fiscalizadora superior.

c Cantidad asignada a la entidad fiscalizadora superior. Por ser imposible distinguir la proporción correspondiente a la contraparte local, se asigna el total al préstamo del BID.

d Operación de crédito en fase de diseño.

CUADRO 3

\section{América Latina: Préstamos del Banco Interamericano de Desarrollo}

(Millones de dólares ${ }^{a}$ y porcentajes)

\begin{tabular}{lccc} 
País & $\begin{array}{c}\text { Presupuesto anual de las } \\
\text { entidades fiscalizadoras superiores } \\
\text { En millones de dólares }\end{array}$ & Préstamos anuales del BID \\
\cline { 3 - 4 } & 242,2 & 1,6 & $\begin{array}{c}\text { Como porcentaje del presupuesto anual } \\
\text { de las entidades fiscalizadoras superiores }\end{array}$ \\
\hline Brasil (2003) & 19,0 & 3,3 & 0,8 \\
Chile (2002) & 54,3 & 5,8 & 1,4 \\
Colombia (2003) & 5,2 & 1,5 & 1,6 \\
Nicaragua (2002) & & & 28,8 \\
\hline
\end{tabular}

Fuente: Elaboración propia con datos de los informes de las entidades fiscalizadoras superiores.

a Debido a la fluctuación del dólar en los últimos años se aconseja precaución al utilizarlo como referente.

estos proyectos innovadores se debe tener en cuenta no sólo su dimensión financiera, sino también su contenido técnico y su enfoque institucional.

En general, los préstamos del BID tienden a concentrarse en mejorar la eficiencia administrativa de las entidades fiscalizadoras superiores mediante el desarrollo estratégico y organizacional; la gestión, capacitación y formación de recursos humanos, y el mejoramiento de la tecnología de la información, los equipos y la infraestructura. También incluyen disposiciones 
para mejorar las relaciones con la sociedad civil. Además, los proyectos del BID hacen marcado hincapié en perfeccionar la fiscalización del cumplimiento de las normas legales y financieras, función central de las entidades fiscalizadoras superiores. En algunos casos, como el de Brasil, contienen también disposiciones respecto a "iniciativas innovadoras", especialmente auditorías de desempeño o ambientales, o técnicas de auditoría para los organismos reguladores de servicios de utilidad pública. Por lo demás, tales préstamos apuntan habitualmente a mejorar la fiscalización operacional de los programas de gobierno, especialmente en el sector social, más que a realzar el papel de las entidades fiscalizadoras superiores en la fiscalización del presupuesto nacional y la certificación parlamentaria de las cuentas públicas. Se piensa, al parecer, que estas últimas funciones centrales de dichas entidades mejorarían de manera natural, aunque no automática, como resultado o efecto secundario del fortalecimiento de tales entidades en su conjunto.

Es entonces paradójico que los préstamos del BID aborden sólo con renuencia los vínculos funcionales entre las entidades fiscalizadoras superiores y las comisiones de cuentas públicas. Como muestra el cuadro 4, la eficacia final de dichas entidades fiscalizadoras está determinada por una serie de factores institucionales, como las facultades conferidas, la autoridad supervisora, los procedimientos para designar y destituir, y el alcance del mandato y su duración. Estas son áreas en las que el BID es reacio a comprometerse. De hecho, las entidades fiscalizadoras superiores en América Latina se caracterizan por su gran diversidad. En Argentina, por ejemplo, el Auditor General de la Nación (AGN) es un órgano colegiado que brinda asesoramiento técnico al parlamento para asegurar la rendición de cuentas por parte del gobierno y la fiscalización del presupuesto; su presidente es designado por el principal grupo opositor en el parlamento. En países como Chile, Perú o Brasil, las entidades fiscalizadoras superiores son nominalmente autónomas, tanto del poder ejecutivo como del legislativo. En Brasil, el Tribunal de Cuentas de la Unión es un órgano colegiado con una larga historia institucional que funge también de tribunal administrativo. Concentra su trabajo de fiscalización en verificar que se cumplan los programas gubernamentales y las tareas de los organismos del gobierno. Por lo tanto, su principal "cliente" es la administración pública a la que fiscaliza. En los países andinos, como Chile y Perú, las entidades fiscalizadoras superiores se definen como instituciones de gobernabilidad, independientes tanto del poder ejecutivo como del legislativo.
Las entidades fiscalizadoras superiores están particularmente expuestas a intromisiones políticas y a la cooptación por intereses partidarios, sobre todo en los sistemas de gobierno presidenciales. La experiencia de la Contraloría General de la República de Perú entre 1993 y 2000 es ilustrativa. Una primera estrategia para evitar tal cooptación es la de reforzar los vínculos funcionales entre las instituciones de rendición de cuentas de carácter horizontal, que forman parte del sistema de fiscalización nacional (O’Donnell 1998; Schedler, Diamond y Plattner, 1999). En consecuencia, las consideraciones de economía política son claves para explicar la eficacia de las entidades fiscalizadoras superiores, concebidas como partes integrales de los sistemas nacionales de control y de prevención de la corrupción.

Una estrategia para impedir la cooptación de las entidades fiscalizadoras superiores consiste en reforzar sus lazos con las otras instituciones que forman parte del sistema nacional de control, especialmente el poder judicial (tribunales administrativos y penales) y el poder legislativo (comisiones de cuentas públicas). Estén o no ligadas nominalmente con los parlamentos, las entidades fiscalizadoras superiores se hallan vinculadas funcionalmente con ellos en la "cadena de supervisión de las finanzas públicas". Esto es evidente en el caso de Colombia, como lo refleja un esfuerzo conjunto del BID y el gobierno colombiano para reforzar la rendición de cuentas del gobierno, la probidad en las finanzas públicas, la fiscalización presupuestaria y el cumplimiento de la ley. En abril de 2003, el BID aprobó un préstamo de 14 millones de dólares (como parte de un programa de 20 millones de dólares) a la Procuraduría General de la Nación, que es la oficina judicial a cargo del control y la disciplina de los organismos públicos. Este programa completa un ciclo de diez años de financiación para modernizar los órganos de control y aplicación de la ley en la administración de las finanzas públicas. En marzo de 2000 se concedió un préstamo de 23 millones de dólares (como parte de un programa de 42 millones de dólares) a las oficinas de la Contraloría General de la República y la Auditoría General de la República, y en diciembre de 1995 se destinaron 9,5 millones de dólares (como parte de un programa de 15,7 millones de dólares) a modernizar la administración de justicia y la Fiscalía General de la Nación. Estos tres préstamos contaron con una financiación de contrapartida considerable (77,7 millones de dólares), que reflejó el compromiso de Colombia con los programas.

Las entidades fiscalizadoras superiores brindan, directa o indirectamente, importantes servicios de 


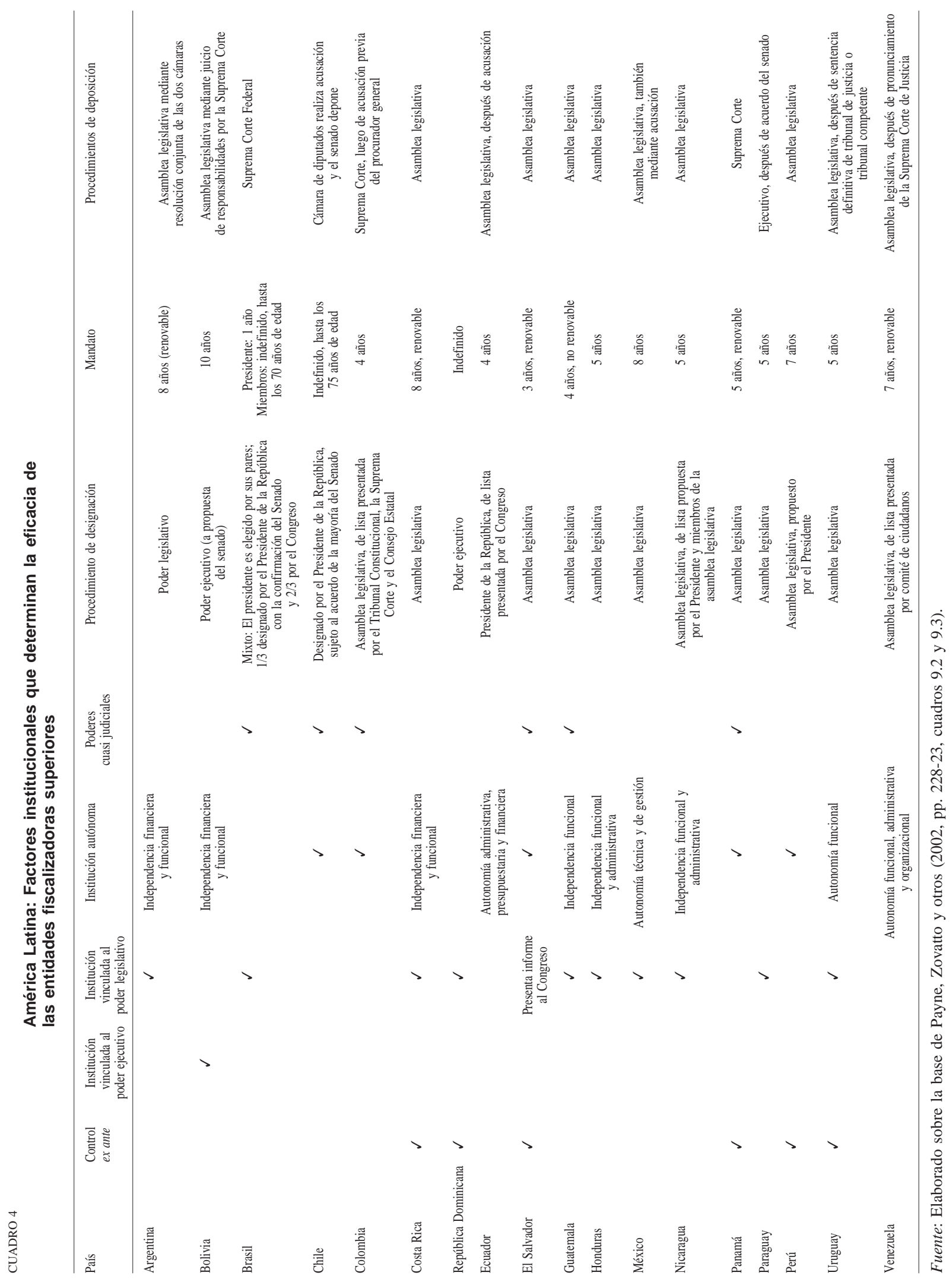


asesoramiento a los parlamentos en el ejercicio de sus funciones ligadas a la rendición de cuentas. Sin embargo, los vínculos entre esas entidades y las comisiones parlamentarias de presupuesto y cuentas públicas son bastante débiles, y se caracterizan, en el mejor de los casos, por una cortés indiferencia. Los préstamos a las entidades fiscalizadoras superiores tienden a pasar por alto la naturaleza disfuncional de las relaciones de tales entidades con los parlamentos. Aunque los préstamos del BID a las asambleas legislativas procuran incrementar la participación de los parlamentos en la política presupuestaria, el respaldo de este banco a las entidades fiscalizadoras superiores tiende a pasar por alto el papel que ellas deben desempeñar en el control y fiscalización del presupuesto. Sólo en unos pocos países, como la República Dominicana en 2000 y El Salvador en 1999, el BID consideró la relación entre las entidades fiscalizadoras superiores y los parlamentos, y otorgó préstamos simultáneos a ambas instituciones. En el caso de la República Dominicana ambos préstamos se fusionaron en uno.

Sin embargo, las operaciones del BID tienden a soslayar el contexto de gobernabilidad más amplio en el que operan las entidades fiscalizadoras superiores, así como los incentivos que condicionan la rendición de cuentas en materia de finanzas públicas. Rara vez procuran potenciar deliberadamente la independencia política y autonomía financiera de esas entidades. Los criterios que orientan la designación y destitución de sus integrantes y la duración de su mandato, así como los procedimientos que regulan la contratación, el ascenso o el despido del personal profesional, son factores esenciales de una efectiva independencia de las entidades fiscalizadoras superiores. La aplicación de criterios de designación fehacientes y la estabilidad en el cargo contribuyen a que los integrantes de las entidades fiscalizadoras superiores actúen con independencia. Además, contar con recursos financieros asegurados es también condición necesaria, aunque no suficiente, para institucionalizar a las entidades fiscalizadoras superiores y protegerlas de la intromisión política (INTOSA, 2001).

La politización del procedimiento para designar a los integrantes de las entidades fiscalizadoras superiores y a su personal representa un gran obstáculo para la efectiva independencia de estas entidades. Cuando el gobierno controla la mayoría en el parlamento, tanto en los sistemas parlamentarios como en los presidenciales las designaciones suelen reflejar transacciones políticas. Además, los mandatos por períodos breves que coinciden con el presidencial tienden a reducir los incentivos para que esos integrantes ejerzan la independencia política que puedan tener. En última instancia, tales incentivos individuales motivan el comportamiento institucional de las entidades fiscalizadoras superiores. En Argentina, por ejemplo, la constitución y la ley sobre administración financiera estipulan que los auditores generales sean designados por un período renovable de ocho años. Sin embargo, para aumentar la independencia del órgano colegiado AGN, en 1994 se estableció mediante una reforma constitucional que su presidente debe pertenecer al principal partido opositor. Como resultado, los presidentes del AGN cambian cada vez que se modifica la mayoría en el gobierno. Además, debido a la extrema politización de la administración pública, hay una alta rotación de personal, lo que ha impedido que se consolide la capacidad técnica y el "espíritu de cuerpo" dentro de esta entidad fiscalizadora superior. Una administración pública preparada y reconocida, que ofrezca estabilidad en el cargo y perspectivas laborales razonables dentro de la institución, es un factor determinante para asegurar el profesionalismo en la auditoría externa de las finanzas del gobierno. ${ }^{14}$

En general, reforzar la capacidad técnica de las entidades fiscalizadoras superiores no significa necesariamente mejorar su eficacia, ni ha impedido que sean cooptadas, como lo ilustra el caso de Nicaragua. Sin embargo, garantizar la independencia real de esas entidades es esencial para poder hacer efectivas las responsabilidades del gobierno, como se recalcó en la declaración de principios de la Organización Internacional de las Entidades Fiscalizadoras Superiores (INTOSAI) en Lima en 1977, y más recientemente en el informe del grupo de trabajo de INTOSAI sobre la fiscalización independiente de los gobiernos (INTOSAI, 2001). Es bien sabido que una deficiencia inherente al Estado en los países en desarrollo es la fragilidad de los mecanismos institucionales para la rendición de cuentas de carácter horizontal anclados en las instituciones estatales cuya función es fiscalizar al gobierno y refrenar al Estado (Mainwaring y Welna, 2003).

\footnotetext{
14 Además, los préstamos del BID han concentrado sus esfuerzos en los niveles nacional o federal. Los mecanismos para la auditoría interna y externa de las finanzas del gobierno son particularmente débiles a nivel local, y con frecuencia son cooptados por las elites del lugar. El BID está apenas comenzando a respaldar a las entidades fiscalizadoras superiores subnacionales en los sistemas federales y a acompañar su desconcentración en los Estados unitarios.
} 


\section{Aspectos políticos de la rendición de cuentas en las finanzas públicas}

Trascurridos ya diez años desde la aparición del tema de la gobernabilidad a la cabeza de la agenda para el desarrollo, se justifican nuevas aproximaciones a la reforma de la gobernabilidad y al desarrollo institucional. En especial, es preciso reducir la brecha entre los aspectos económicos y políticos de la financiación multilateral para el desarrollo. El estudio de la posición del BID con respecto a la modernización de la administración financiera es particularmente ilustrativo, por ser éste el más político de los bancos multilaterales de desarrollo.

Todavía es difícil saber cuáles han sido los efectos de los préstamos otorgados por el BID a parlamentos y entidades fiscalizadoras superiores. Como señala Kaufmann (2003, p. 3), 'debemos tener en cuenta que este esfuerzo se ha realizado en el contexto de un bajo desarrollo relativo en el complejo y multidisciplinario campo de la gobernabilidad y la lucha contra la corrupción' ${ }^{15}$ La evaluación de los resultados plantea varias dificultades. Primero, hay que definir indicadores de impacto para este nuevo tipo de proyecto destinado deliberadamente al fortalecimiento institucional. Segundo, y aún más importante, es preciso establecer indicadores que midan el desempeño y el impacto final de las propias instituciones de control. Y tercero, hay que determinar hasta qué punto y en qué forma hay que encarar los aspectos políticos de la rendición de cuentas en las finanzas públicas. Al hacer todo esto, el número y la diversidad de variables explicativas se amplía considerablemente. Reconocer la importancia de los aspectos políticos de la elaboración presupuestaria y de la economía política de la rendición de cuentas en las finanzas públicas es sin duda un paso adelante.

No obstante, al otorgar préstamos a los parlamentos nacionales y a las entidades fiscalizadoras superiores, el BID muestra cierta renuencia a involucrarse en la economía política de la rendición de cuentas presupuestaria y en los aspectos políticos de la integridad en las finanzas públicas. La mayor parte de la finan-

\footnotetext{
${ }^{15}$ En este artículo las citas entre comillas simples corresponden a
} traducciones del inglés. ciación otorgada por el BID a las entidades de control presupuestario se destina a inversiones materiales, como la creación de infraestructura, a la tecnología de la información y a la gestión de recursos humanos. En un pasado más reciente, el respaldo del BID también apuntó a modificar los procedimientos y reforzar las estructuras que enmarcan el proceso presupuestario en el parlamento, como las comisiones de presupuesto y finanzas, y los servicios de investigación y oficinas de presupuesto parlamentarios. Sólo unos pocos parlamentos de países latinoamericanos, entre ellos los de Brasil, Chile, Perú y Venezuela, cuentan con capacidad de investigación y de asesoramiento independientes. En estos casos el BID recomienda afianzar esa capacidad, mientras aboga por que se establezca allí donde no existe.

Los organismos financieros internacionales justifican su enfoque apolítico aduciendo que las mejoras técnicas que se introduzcan pueden, con el tiempo, contribuir a mejorar la gobernabilidad, sin perderse en las complejidades de la política. El hecho de considerar la gobernabilidad como un tema técnico les ha permitido justificar su participación en temas de gobernabilidad, sin sobrepasar sus respectivos mandatos. No obstante, hay límites para este consenso tecnocrático. El enfoque funcionalista descrito crea la ilusión de que las soluciones técnicas pueden resolver los problemas políticos. Pero las reformas institucionales en la elaboración del presupuesto público son intrínsecamente políticas (Shepsle, 1999; Wildavsky, 1964 y 1992). Aunque en general se formulan en el lenguaje de la eficiencia, las reformas de las finanzas públicas afectan las relaciones de poder, dado que el presupuesto es un escenario clave para la negociación política. Las decisiones sobre quién controla el proceso presupuestario y cómo se determinan las asignaciones presupuestarias son intrínsecamente políticas. Por lo tanto, el intento de separar las facetas económicas y políticas de la elaboración del presupuesto público es, en gran medida, artificial. Como subraya Kaufmann (2003, p. 33), 'la adecuada comprensión de las fuerzas políticas que afectan a la formulación de políticas y, lo que está relacionado, del conjunto de incentivos institucionales necesarios para 
el progreso' son fundamentales para entender la dinámica de la reforma presupuestaria.

El BID (2003, p. 9) reconoce de hecho que los "proyectos limitados a cambiar los elementos instrumentales o a fortalecer simplemente capacidades técnico-organizativas, sin alterar la estructura de incentivos que afectan a la voluntad política de aplicar estos nuevos instrumentos o capacidades, tienen por lo general un impacto muy reducido. Esto supone la necesidad de contemplar al mismo tiempo cambios que condicionan la efectividad de las alteraciones instrumentales y organizacionales. Por ejemplo, de poco sirve [...] promover sistemas de gestión financiera sin el desarrollo de una autoridad presupuestaria con la independencia profesional, el poder y la capacidad de hacerlos cumplir." En efecto, las iniciativas de reforma fracasan no sólo porque son incompletas, sino también porque con frecuencia se conciben para resolver dificultades técnicas cuando en realidad el problema está en el marco institucional.

Es preciso asegurar una más amplia comprensión de la gestión del proceso presupuestario. Las entidades fiscalizadoras superiores y las comisiones de cuentas públicas ocupan posiciones clave en la administración de las finanzas públicas (Wehner, 2003; Petri, 1998). La calidad del control parlamentario de las finanzas gubernamentales depende esencialmente de la disponibilidad de información fiable y de análisis independientes del presupuesto, proporcionados con regularidad por las entidades fiscalizadoras superiores. Al mismo tiempo, la eficacia y los resultados finales de la labor de estas entidades dependen en gran medida de que los parlamentos apliquen las recomendaciones contenidas en los informes de auditoría que ellas elaboran. De aquí que sea crucial la calidad del vínculo funcional y las relaciones institucionales entre las comisiones de cuentas públicas del parlamento y las entidades fiscalizadoras superiores (sIGMA, 2002). Asimismo, la capacidad de estas entidades para cumplir con su mandato depende en gran medida de su independencia de los gobiernos y, al mismo tiempo, de la cooperación que presten los organismos gubernamentales.

Las relaciones entre las entidades fiscalizadoras superiores y las comisiones de cuentas públicas son decisivas para asegurar una efectiva rendición de cuentas por parte del gobierno. La eficacia que en definitiva tengan unas y otras se deberá en gran medida a los mecanismos institucionales y las estructuras de incentivos. En primer lugar, los informes y las recomendaciones de las entidades fiscalizadoras superiores son inútiles si no son llevados a la práctica por otras ins- tituciones que forman parte del sistema de control, en especial la propia administración pública (responsabilidades administrativas), el poder judicial (responsabilidades penales) y el parlamento (responsabilidades políticas). Su eficacia, por lo tanto, está condicionada a la cooperación de otras instituciones estatales. Además, en muchos casos, sobre todo en los sistemas de gobierno presidenciales, para nombrar a los integrantes de las entidades fiscalizadoras superiores se necesita el consentimiento de una mayoría calificada de parlamentarios (con frecuencia de dos tercios), que incluye al partido gobernante. Las transacciones políticas que tienen lugar suelen socavar la independencia política del candidato elegido.

En segundo lugar, la disposición de las comisiones de cuentas públicas a ejercer sus poderes y pedir cuentas al gobierno también está determinada por factores de gobernabilidad más amplios. Estas comisiones son un reflejo del accionar político en el parlamento y de la naturaleza de las relaciones entre el ejecutivo y el legislativo (Morgenstern y Nacif, 2002). En efecto, su composición refleja la del propio parlamento y, por lo tanto, el partido gobernante suele controlarlas. A diferencia de lo que sucede en sistemas de gobierno parlamentarios, en los cuales dichas comisiones son presididas por un representante de la oposición, en América Latina la presidencia de las comisiones de presupuesto y cuentas públicas tradicionalmente recae en un miembro del partido gobernante. De hecho, puede aducirse que la eficacia de los mecanismos de rendición de cuentas de carácter horizontal depende en última instancia de la efectividad de los mecanismos de rendición de cuentas de carácter vertical, en particular las normas electorales y las estructuras partidarias.

El comportamiento mismo de los miembros del parlamento está determinado por los incentivos a los cuales ellos responden. Las relaciones entre el poder ejecutivo y el legislativo pasan necesariamente por la intermediación de los partidos políticos y las normas electorales, dado que existe la posibilidad de que el control se diluya cuando el partido o coalición gobernante tiene una posición mayoritaria en el parlamento. Investigaciones recientes sobre los aspectos políticos de la elaboración del presupuesto en Brasil ${ }^{16}$ muestran que la participación del poder legislativo en el proceso presupuestario sólo puede entenderse cuando se tienen en cuenta los partidos políticos y las normas

16 Véase Mainwaring y Welna (2003), Morgenstern y Manzetti (2003) y Figueiredo (2001 y 2003). 
electorales. Puesto que el poder ejecutivo domina la elaboración del presupuesto y controla su ejecución, la participación de los partidos en el proceso presupuestario depende de sus relaciones con el ejecutivo (Pereira y Mueller, 2002). En efecto, los mecanismos de rendición de cuentas en sistemas de gobierno presidenciales que aúnan el peso del ejecutivo y las mayorías legislativas tienden a ser ineficaces.

Por lo tanto, existe un potencial inexplorado en la asistencia que brindan los bancos multilaterales de desarrollo a las entidades fiscalizadoras superiores y a las comisiones parlamentarias de cuentas públicas de América Latina. La segunda fase del respaldo multilateral a las instituciones presupuestarias debería encaminarse a fortalecer la independencia política y la autonomía financiera de las entidades fiscalizadoras superiores y a promover vínculos más eficaces entre éstas y las comisiones parlamentarias de cuentas públicas. El análisis de los préstamos del BID con frecuencia revela que no se consideraron tales vínculos en el diseño de sus intervenciones. En general, las operaciones crediticias del BID tienden a concebirse como intervenciones autónomas. Esto tiene la ventaja de protegerlas de interferencias externas injustificadas, pero también la desventaja de impedir las sinergias entre ellas.

Por lo demás, las instituciones financieras internacionales también deberían concebir iniciativas integradas que abarquen todo el ciclo presupuestario y la gestión y supervisión del proceso presupuestario en su conjunto. Para hacerlo habría que coordinar los proyectos que apuntan a modernizar los sistemas de información sobre las finanzas públicas dentro del ejecutivo con aquellos orientados a realzar el papel de las entidades fiscalizadoras superiores y de las comisiones parlamentarias. También habría que vincular de manera más metódica las medidas para mejorar la administración de las finanzas públicas y la rendición de cuentas públicas, con aquellas que apuntan a consolidar el Estado de derecho, reformar la administración pública, fortalecer las asambleas legislativas y combatir la corrupción.

Más importante aún, al otorgar préstamos multilaterales para fortalecer las instituciones de control presupuestario es preciso aprovechar la dinámica de poder estructural. Como recalca Messick (2002, p. 1), "para tener éxito es preciso cambiar los incentivos a los funcionarios públicos [...] La estructura constitucional y la cohesión partidaria son factores clave para la independencia de la asamblea legislativa'. Es probable que las acciones para acrecentar la capacidad técnica y analítica mediante la creación o desarrollo de servicios de investigación parlamentarios o el perfeccionamiento de las técnicas de investigación en las instituciones fiscalizadoras continúen siendo ineficaces, mientras no exista suficiente espacio político para que estos recursos sean utilizados de manera efectiva. También es probable que los avances técnicos se vean limitados por dinámicas políticas adversas y restricciones en materia de gobernabilidad. La cuestión fundamental es dilucidar si el hecho de dotar de mayor capacidad técnica a las entidades fiscalizadoras las fortalecería, o si una mayor independencia y asertividad las llevaría a crear y utilizar más capacidad técnica. El enfoque del BID tiende a confiar en la primera teoría, y se concentra en mejorar la capacidad técnica de las instituciones. No obstante, hay razones para creer que la segunda teoría puede ser una buena orientación complementaria, y es por eso que figura en la nueva estrategia para reformar el Estado y modernizar el gobierno adoptada en 2003 por el BID. ${ }^{17}$

(Traducido del inglés)

\section{Bibliografía}

Ahrens, J. (2001): Governance, conditionality and transformation in post-socialist countries, en H. Hoen (comp.), Good Governance in Central and Eastern Europe, Cheltenham, Edward Elgar.

BAfD (Banco Africano de Desarrollo) (2000): Good Governance Policy, Abidjan.

Banco Mundial (1992): Governance and Development, Washington, D.C.

(1997): World Development Report 1997: The State in a Changing World, Nueva York, Oxford University Press. (2000): Reforming Public Institutions and Strengthening Governance: A World Bank Strategy, Washington, D.C.

BAsD (Banco Asiático de Desarrollo) (1995): Governance: Sound Development Management, Manila, agosto.
(1999): Governance in Asia: from crisis to opportunity, Annual Report 1998, Manila.

BERD (Banco Europeo de Reconstrucción y Desarrollo) (1992): Political Aspects of the Mandate of the EBRD, Londres.

BID (Banco Interamericano de Desarrollo) (1996): Marco de referencia para la acción del Banco en los programas de modernización del estado y fortalecimiento de la sociedad civil, 3/96, GN-1883-5, Washington, D.C.

(2003): Modernización del Estado: documento de estrategia, 7/03, GN-2235-1, Washington, D.C.

\footnotetext{
17 Véase BID (2003).
} 
Biebesheimer, C. y M. Payne (2001): IDB Experience in Justice Reform: Lessons Learned and Elements for Policy Formulation, Technical Paper Series, Washington, D.C., Banco Interamericano de Desarrollo (BID).

Brobäck, U. y S. Sjölander (2002): Programme Support and Public Finance Management: A New Role for Bilateral Donors in Poverty Strategy Work, Sida Studies, $\mathrm{N}^{\circ}$ 6, Estocolmo, Organismo Sueco de Desarrollo Internacional (OSDI).

Burki, S.J., G. Perry y otros (1998): Beyond the Washington Consensus. Institutions Matter, Washington, D.C., Banco Mundial.

Carbonell, M. (2002): Los conflictos entre el poder legislativo y el poder ejecutivo en México, Contribuciones, $\mathrm{N}^{\mathrm{o}} 3$, Buenos Aires, Centro Interdisciplinario de Estudios sobre el Desarrollo Latinoamericano (CIEDLA).

DFID (Department for International Development) (2001): Understanding and Reforming Public Expenditure Management, Londres.

(2002): Managing Fiduciary Risk when Providing Direct Budget Support, Londres.

Diamond, J. (2002): The Role of Internal Audit in Government Financial Management: An International Perspective, documento de trabajo, WP/02/94, Washington, D.C., Departamento de Asuntos Fiscales, Fondo Monetario Internacional (FMI), mayo.

Dorotinsky, W. y Y. Matsuda (2002): Reforma de la gestión financiera en América Latina: una perspectiva institucional, Reforma y democracia, $\mathrm{N}^{\circ} 23$, Caracas, Centro Latinoamericano de Administración para el Desarrollo (CLAD).

Drake, P. (1989): Money Doctor in the Andes: the Kemmerer Missions, 1923-1933, Durham, Duke University Press.

Eaton, K. (2002): Fiscal policy making in the Argentine legislature, en S. Morgenstern y B. Nacif (comps.) (2002): Legislative Politics in Latin America, Cambridge, Cambridge University Press.

Figueiredo, A. (2001): Instituições e política no controle do executivo, Dados, vol. 44, $\mathrm{N}^{\circ}$ 4, Rio de Janeiro, Instituto Universitário de Pesquisas do Rio de Janeiro.

(2003): The role of Congress as an agency of horizontal accountability: lessons from the Brazilian experience, en S. Mainwaring y C. Welna (comps.) (2003): Democratic Accountability in Latin America, Oxford, Oxford University Press.

FMI (Fondo Monetario Internacional) (1997): Good Governance: The IMF's Role, Washington, D.C.

(2001): Review of the Fund's Experience in Governance Issues, Washington, D.C.

Fuhr, H. y P. Krause (2003): Overview of Core Public Sector Reform Projects 1982-2002, Washington, D.C., Banco Mundial.

Haggard, S. y M.D. McCubbins (comps.) (2001): Presidents, Parliaments, and Policy, Cambridge, Cambridge University Press.

INTOSAI (Organización Internacional de las Entidades Fiscalizadoras Superiores) (2001): Independence of Supreme Audit Institutions: Final Task Force Report, Viena, Secretaría General.

Jones, M. (2001): Political institutions and public policy in Argentina: an overview of the formation and execution of the national budget, en S. Haggard y M.D. McCubbins (comps.), Presidents, Parliaments, and Policy, Cambridge, Cambridge University Press.

Kaufmann, D. (2003): Rethinking governance: Empirical lessons challenge orthodoxy, Discussion draft, Washington, D.C., Banco Mundial, marzo.

Krafchik, W. y J. Wehner (1998): The role of parliaments in the budget process, South African Journal of Economics, vol. 66, $N^{\circ} 4$, Lynwood Ridge, Economic Society of South Africa (ESSA).
Krueger, A. (comp.) (2000): Economic Policy Reform: The Second Stage, Chicago, University of Chicago Press.

Kuczynski, P. y J. Williamson (comps.) (2003): After the Washington Consensus: Restarting Growth and Reform in Latin America, Washington, D.C., Institute for International Economics (IIE).

Llanos, P. (2002): La entidades fiscalizadoras superiores y la cooperación internacional, documento presentado en las II Jornadas Euroamericanas de Entidades Fiscalizadoras Superiores EUROSAI-OLACEFS (Cartagena de Indias, Colombia, 11 de julio).

Mainwaring, S. y C. Welna (comps.) (2003): Democratic Accountability in Latin America, Oxford, Oxford University Press.

Manning, N. y R. Stepenhurst (2002): Strengthening Oversight by Legislatures, PREM Note, $\mathrm{N}^{\circ}$ 74, Washington, D.C., Banco Mundial, octubre.

Messick, R. (2002): Strengthening Legislatures: Implications from Industrial Countries, PREM Note, $\mathrm{N}^{\circ} 63$, Washington, D.C., Banco Mundial.

Morgenstern, S. y L. Manzetti (2003): Legislative oversight: interests and institutions in the United States and Argentina, en S Mainwaring y C. Welna (comps.) (2003): Democratic Accountability in Latin America, Oxford, Oxford University Press.

Morgenstern, S. y B. Nacif (comps.) (2002): Legislative Politics in Latin America, Cambridge, Cambridge University Press.

OCDE (Organización de Cooperación y Desarrollo Económicos) (1998): The Role of the Legislature, París.

(2001a): OECD Best Practices for Budget Transparency, OECD PUMA/SBO(2000)6/FINAL, París.

(2001b): Budget: Towards a New Role for the Legislature, París.

O’Donnell, G. (1998): Horizontal accountability in new democracies, Journal of Democracy vol. 9, $\mathrm{N}^{\circ}$ 3, Baltimore, Maryland, The Johns Hopkins University Press.

Payne, M., D. Zovatto y otros (2002): Democracies in Development: Politics and Reform in Latin America, Washington, D.C., Banco Interamericano de Desarrollo (BID).

Pereira, C. y B. Mueller (2002): Comportamento estratégico em presidencialismo de coalizão: as relações entre executivo e legislativo na elaboração do orçamento brasileiro, Dados, vol. $45, \mathrm{~N}^{\mathrm{o}} 2$, Rio de Janeiro, Instituto Universitário de Pesquisas do Rio de Janeiro.

Petri, H. (1998): Budget and Control: Reforming the Public Sector in Latin America, Washington, D.C., Banco Interamericano de Desarrollo (BID).

PEFA (Public Expenditure and Financial Accountability) (2003): Assessing Public Expenditure, Procurement and Financial Accountability: A Review of the Diagnostic Instruments, Washington, D.C

Rojas, E. y H. Zavarce (2004): Instituciones para la coordinación de la política monetaria y fiscal: un enfoque transaccional para el caso venezolano, documento presentado al XVI Seminario Regional de Política Fiscal (CEPAL, Santiago de Chile, 26-29 de enero de 2004).

Rubio Llorente, F. (1993): La forma del poder, Madrid, Centro de Estudios Constitucionales.

Samuels, D. (2002): Progressive ambition, federalism and porkbarreling in Brazil, en S. Morgenstern y B. Nacif (comps.) (2002): Legislative Politics in Latin America, Cambridge, Cambridge University Press.

Santiso, C. (s/f): The Governance of the Budget in Emerging Economies: Institutions of Accountability, Oversight and Anticorruption in Public Finance, inédito.

(2000): Towards democratic governance: the contribution of the multilateral development banks in Latin America, en P. Burnell (comp.), Democracy Assistance: International Cooperation for Democratization, Londres, Frank Cass. 
(2001a): Gobernabilidad democrática y reformas económicas de segunda generación en América Latina, Instituciones y desarrollo, $\mathrm{N}^{\circ} 8-9$, Barcelona, Instituto Internacional de Gobernabilidad, mayo.

(2001b): Gobernabilidad democrática y política económica insular: paradojas de las reformas de segunda generación en la Argentina de los 1990, Contribuciones, año 18, N 4(72), Buenos Aires, Centro Interdisciplinario de Estudios sobre el Desarrollo Latinoamericano (CIEDLA), diciembre.

(2001c): Good governance and aid effectiveness: The World Bank and conditionality, Georgetown Public Policy Review, vol. 7, № 1, Washington, D.C., Georgetown University.

(2003a): Another lost decade? The future of reform in Latin America, Public Administration and Development, vol. 23, $\mathrm{N}^{\mathrm{o}} 4$, Nueva York, John Wiley and Sons.

(2003b): The elusive search for the rule of law: promoting judicial reform in Latin America, Brazilian Journal of Political Economy, vol. 23, $\mathrm{N}^{\mathrm{o}}$ 3, São Paulo.

(2004a): Re-forming the State: governance institutions and the credibility of economic policymaking, International Public Management Journal, vol. 7, $\mathrm{N}^{\circ} 3$, International Public Management Network, en prensa.

(2004b): Legislative Budget Oversight and Public Finance Accountability in Presidential Systems: Governance of the Budget in Peru, documento preparado para el XVI Seminario Regional de Política Fiscal (CEPAL, Santiago de Chile, 26-29 de enero de 2004).

(2004c): The contentious Washington Consensus: reforming the reforms in emerging markets, Review of International Political Economy, Londres, Routledge, en prensa. (2004d): The political economy of governance and conditionality in multilateral development finance, International Public Management Journal, vol. 7, № 1, International Public Management Network, en prensa.

Schedler, A., L. Diamond y M. Plattner (comps.) (1999): The SelfRestraining State: Power and Accountability in New Democracies, Boulder, Colorado, Lynne Rienner.

Shepsle, K. (1999): The political economy of state reform: political to the core, Brazilian Journal of Political Economy, vol. 19,

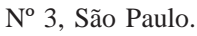

SIGMA (Support for Improvement in Governance and Management) (2002): Relations between Supreme Audit Institutions and Parliamentary Committees, SIGMA Paper, $N^{\circ} 33$, CCNM/GOV/ SigMA(2002)1, París.

TCU (Tribunal de Contas da União) (2002): Relátorio das actividades do TCU, 3 Trimestre de 2002, Brasilia, D.F.

Wehner, J. (2002): Best practices in public accounts committees, inédito.

(2003): Back from the sidelines? Redefining the contribution of legislatures to the budget cycle, inédito.

Weldon, J. (2002): Legislative delegation and the budget process in Mexico, en S. Morgenstern y B. Nacif (comps.) (2002): Legislative Politics in Latin America, Cambridge, Cambridge University Press.

Wildavsky, A. (1964): The Politics of the Budgetary Process, Boston, Little, Brown.

(1992): Political implications of budget reform: a retrospective, Public Administration Review, $\mathrm{N}^{\circ}$ 52, Oxford, Blackwell Publishing. 